\title{
Expression of proliferation associated antigens and detection of numerical chromosome aberrations in primary human liver tumours: relevance to tumour characteristics and prognosis
}

\author{
M Nolte, M Werner, A Nasarek, H Bektas, R von Wasielewski, J Klempnauer, A Georgii
}

\begin{abstract}
Aims-To assess cell proliferation and the presence of numerical chromosome aberrations involving chromosomes 1 and 8 in benign and malignant liver tumours.

Methods-Cell proliferation was studied immunohistochemically in paraffin wax embedded material from 62 primary liver tumours (20 hepatocellular carcinomas, 16 cholangiocellular carcinomas, 15 liver cell adenomas, 11 focal nodular hyperplasias), and the results were compared with histological characteristics and clinical data. Copy numbers of chromosomes 1 and 8 were assessed by interphase fluorescence in situ hybridisation (FISH) with satellite probes in fresh tumour material. Results-The expression of proliferation associated antigen Ki67, using the monoclonal antibody MIB-1, and proliferating cell nuclear antigen (PCNA), using the antibody PC10, was found to be significantly higher in malignant versus benign liver tumours. Neither Ki67 nor PCNA expression were independent prognostic parameters. However, there was a tendency for a worse outcome (survival $<12$ months) for patients with a high MIB-1 labelling index $(>20 \%)$ compared with patients having the same tumour stage and a low MIB-1 index. Aneusomy for chromosomes 1 and 8 was demonstrated by FISH in malignant tumours (six of seven hepatocellular carcinomas, four of five cholangiocellular carcinomas) but not in benign tumours (none of nine) or non-neoplastic liver (none of nine).

Conclusion-Both the determination of the proliferating cell fraction and FISH analysis are useful for distinguishing hepatocellular carcinoma from liver cell adenoma or focal nodular hyperplasia; high fractions of proliferating cells are predictive of an early relapse. (F Clin Pathol 1998;51:47-51)
\end{abstract}

Keywords: hepatocellular carcinoma; cholangiocarcinoma; liver cell adenoma; focal nodular hyperplasia; immunohistochemistry; fluorescence in situ hybridisation; proliferation antigens

Cell cycle associated antigens have gained some attention in diagnostic pathology during the past few years because they may be of prognostic value for tumour patients. One of the best characterised markers of proliferation is the Ki67 antigen, which can be detected reliably by the monoclonal antibody MIB-1 in paraffin wax embedded sections. ${ }^{12}$ Another antibody, PC10, which detects the proliferating cell nuclear antigen (PCNA), ${ }^{34}$ has come under intensive discussion, because results vary considerably according to various technical parameters. ${ }^{56}$ Whereas it is accepted that Ki67 expression mirrors the proliferative activity of cells, the usefulness of PCNA for assessing proliferation is unclear. ${ }^{5-8}$ So far, only a few studies have investigated the proliferative capacity of human liver tumours, ${ }^{9-13}$ and some have suggested a correlation between growth fraction and histological characteristics or biological tumour behaviour.

Interest in the pathology of tumours of the liver has increased because of the relatively successful methods of curative liver surgery that have been established. ${ }^{14}$ Few articles have been dedicated to investigating the proliferative conditions of the various primary tumours that occur in the liver. The question of correlation between histological grade and pattern and its growth fraction still requires detailed consideration.

In a variety of tumours, karyotype anomalies have been shown to be related directly to clinical outcome, ${ }^{15}$ so that it would seem useful to support data on the proliferation rate with cytogenetic characterisation of the tumour cells.

Little is known about characteristic karyotype anomalies of primary liver cancer, but chromosome 1 and 8 abnormalities in hepatocellular carcinoma have been suggested by karyotyping results. ${ }^{16-20}$ Because karyotyping is rather complicated in neoplastic liver cells, ${ }^{16} 1719$ fluorescence in situ hybridisation (FISH), which analyses numerical chromosome changes with chromosome specific DNA probes, appears to be a better approach, especially as it can also analyse interphase cells. ${ }^{20}{ }^{21}$ The present study aimed at determining the proliferation index together with the numerical chromosome changes in primary tumours of the liver. These results were correlated with histology, classification of tumours regarding pTNM staging, and survival times.

\section{Material and methods}

PATIENTS AND TUMOUR TISSUES

Biopsy material from 62 primary liver tumours was fixed routinely in $10 \%$ buffered formalin, embedded in paraffin wax, and $4 \mu \mathrm{m}$ sections were mounted on poly-L-lysin coated slides 
Table 1 MIB-1 and PCNA indexes

\begin{tabular}{lllr}
\hline & \multirow{2}{*}{$\begin{array}{l}\text { Number } \\
\text { Tf cases }\end{array}$} & \multicolumn{2}{l}{ Labelling index (mean (SD)) (\%) } \\
\cline { 3 - 4 } & & \multicolumn{1}{l}{$M I B-1$} & \multicolumn{1}{c}{ PCNA } \\
\hline Normal liver & 5 & $<1$ & $10.8(8.7)$ \\
Cirrhotic liver & 6 & $<1$ & $8.8(6.7)$ \\
Adenoma & 15 & $1.1(0.3)$ & $2.8(4.0)$ \\
Focal nodular hyperplasia & 12 & $1.1(0.3)$ & $3.0(1.7)$ \\
Hepatocellular carcinoma & 20 & $19.4(15.3)$ & $48.4(20.3)$ \\
Cholangiocellular carcinoma & 15 & $26.8(17.5)$ & $56.2(14.6)$ \\
\hline
\end{tabular}

(Sigma, Deisenhofen, Germany). Routine histopathology was performed based on haematoxylin and eosin stained sections as well as periodic acid Schiff staining and immunohistochemistry (cytokeratins 7, 8, 18, 19, carcinoembryonic antigen, epithelial membrane antigen, $\alpha$ fetoprotein) where necessary. Of the 62 tumours examined, 20 were hepatocellular carcinomas, 16 were cholangiocarcinomas (including nine extrahepatic Klatskin-tumours and seven intrahepatic bile duct carcinomas), 15 were liver cell adenomas, and 11 were focal nodular hyperplasias. In addition, six cirrhoses of the liver and five normal liver tissues were included as non-neoplastic controls. Grading of hepatocellular carcinoma was performed according to the criteria of Edmondson and Steiner. ${ }^{22}$ Clinical data (including survival and disease free survival) were available for 32 patients (20 with hepatocellular carcinomas, 12 with cholangiocellular carcinomas). At the time of surgery, in most hepatocellular carcinoma patients (14 of 20) an advanced tumour stage was diagnosed (three pT3, 11 pT4). Of the cholangiocellular carcinomas, there were four pT2 tumours, six pT3 tumours, and one pT4 tumour. The mean observation period for the 32 patients with follow up after surgical removal of the tumour was 49 months. At that time, 13 of 20 hepatocellular carcinoma patients and 8 of 12 cholangiocellular carcinoma patients had died.

Ki67 AND PCNA IMMUNOHISTOCHEMISTRY

Sections were deparaffinised in xylene, rehydrated through graded ethanol, and washed in Tris buffered saline (TBS) before staining. Non-specific binding was blocked by incubating the sections for 30 minutes in diluted normal serum (Dako, Hamburg, Germany). Staining with the antibody MIB-1 (Dianova, Hamburg, Germany; FRG; dilution 1/100), which recognises a formalin resistant epitope of the Ki67 antigen, as well as with PC10, directed against the PCNA protein (Dianova; dilution $1 / 50$ ), was carried out after microwave pretreatment of sections in $0.1 \mathrm{M}$ citrate monohydrate $(\mathrm{pH}$ ) for 30 minutes. For detection, the alkaline phosphatase anti-alkaline phosphatase (APAAP) technique was applied using New Fuchsin as the substrate. ${ }^{23}$ Four representative areas of each section were chosen for counting the immunoreactive cells, and at least 200 cells from each area were evaluated with the aid of an eyegrid. The mean values of all cells examined from each specimen were used to determine the labelling index, defined as the number of antigen positive cells among all the cells counted. Only nuclear staining was regarded as positive.

FISH ANALYSIS

In one third of the cases $(n=21)$, fresh material from the tumours (seven hepatocellular carcinomas, five cholangiocellular carcinomas, five liver cell adenomas, and four focal nodular hyperplasias) was available for FISH analysis. In the remainder of the cases, non-neoplastic liver tissue was also obtained directly after surgical removal for FISH analysis. Touch imprints were made of these specimens on poly-L-lysine coated slides, which were then fixed in paraformaldehyde ( $4 \%$ in phosphate buffered saline) for 10 minutes. The slides were either used directly or stored at $-20^{\circ} \mathrm{C}$ until hybridisation. FISH with biotin labelled probes specific for the pericentromeric regions of chromosomes 1 or 8 (locus D1Z5 and D8Z1, respectively; Oncor, Gaithersburg, Maryland, USA) was performed as described previously. ${ }^{20}$ Cells were counterstained with propidium iodide and viewed with a Zeiss Axiophot epifluorescence microscope at a magnification of $\times 1000$. At least 100 cells were inspected, and the number of signals per nucleus was counted. Metaphases prepared from peripheral blood lymphocytes of a healthy male donor were used as a control for the specificity of each reaction.

\section{STATISTICS}

Mean values, standard deviations, ranges, and the Pearson correlation coefficient were determined. The data were analysed using the student's $t$ test and the $\chi^{2}$ test and statistical significance was set at $\mathrm{p}$ values $<0.05$.

\section{Results}

IMMUNOHISTOCHEMISTRY

The PC10 and MIB-1 antibodies showed similar staining patterns although there were approximately twice as many PCNA positive cells as Ki67 positive cells (table 1). The intensity of PC10 immunoreactivity was more variable than that of MIB-1, ranging from intense red staining to very faint reactions, making it difficult to decide whether a given nucleus should be regarded as positive or not. Occasionally, bile duct epithelia, endothelial cells, Kupffer's cells, or scattered infiltrating inflammatory cells showed positivity for the PC10 and MIB-1 antibodies, sometimes making it difficult to distinguish them from tumour parenchymal cells. However, in general, the nuclei of non-tumour cells could be distinguished clearly by their smaller and uniform nuclei. The positivity rates for both antibodies were significantly higher in hepatocellular carcinoma than liver cell adenoma or focal nodular hyperplasia (PC10, p $<0.001$; MIB-1, $\mathrm{p}<0.008$ ) (table 1 ; figs 1 and 2). In cholangiocellular carcinoma, MIB-1 and PC10 displayed staining rates comparable to those obtained in hepatocellular carcinoma (table 1). With MIB-1, in both cirrhosis of the liver and normal liver less than $1 \%$ of all cells were positive, whereas PC10 displayed labelling indices of $8.8 \%$ and $10.8 \%$, respectively. 


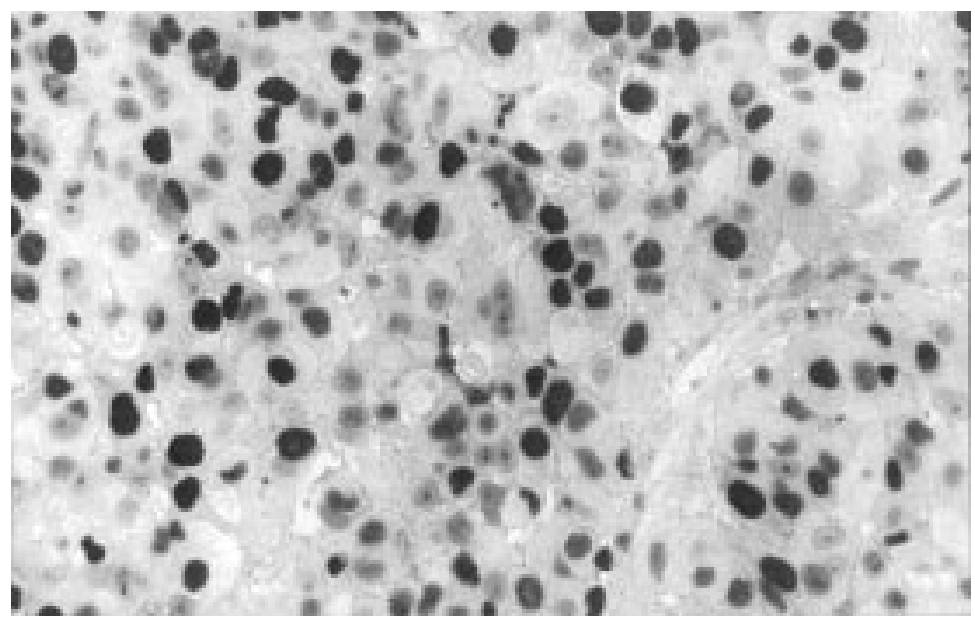

Figure 1 Immunostaining with MIB-1 in a hepatocellular carcinoma. (APAAP method, haematoxylin counterstain; original magnification $\times 360$.)

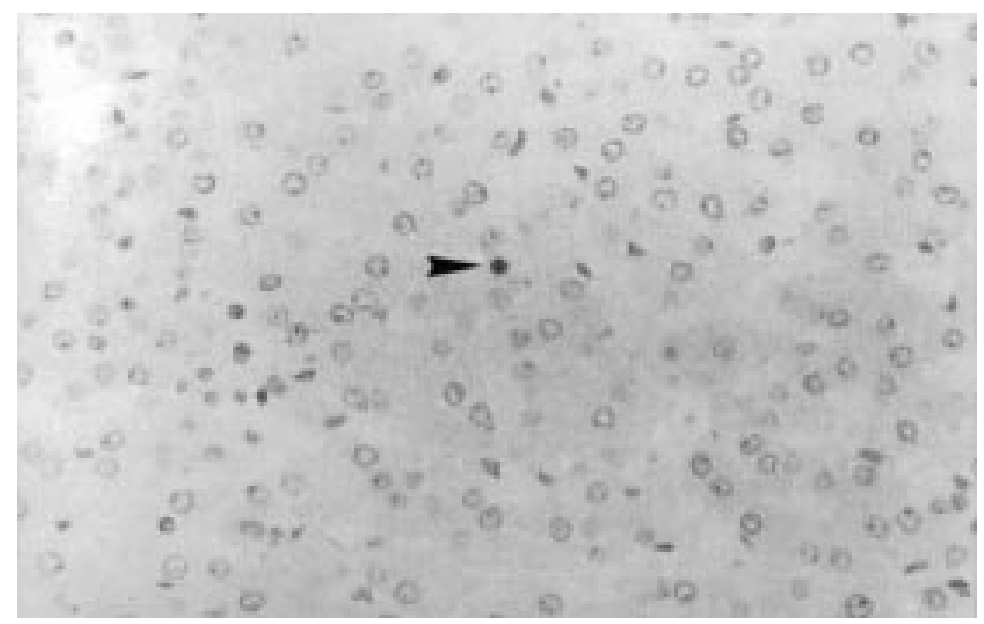

Figure 2 Immunostaining with MIB-1 in a liver cell adenoma displaying only one positive cell (arrow). (APAAP method, haematoxylin counterstain; original magnification $\times 360$.)

Table 2 Results of patients with hepatocellular carcinoma related to survival

\begin{tabular}{|c|c|c|c|c|c|c|}
\hline Case & $\begin{array}{l}\text { Survival } \\
\text { (months) }\end{array}$ & $\begin{array}{l}\text { Tumour } \\
\text { stage }\end{array}$ & Grade & $\begin{array}{l}\text { MIB-1 } \\
\text { index (\%) }\end{array}$ & $\begin{array}{l}\text { Chromosome } 1 \\
\text { (FISH) }\end{array}$ & $\begin{array}{l}\text { Chromosome } 8 \\
\text { (FISH) }\end{array}$ \\
\hline 1 & $5(\mathrm{D})^{\star}$ & pT2 & III & 6 & Disomy & Trisomy \\
\hline 2 & 8 (D) & pT3 & IV & 42 & Trisomy & - \\
\hline 3 & 4 (D) & pT4 & III & 34 & - & - \\
\hline 4 & 7 (D) & pT4 & III & 56 & Trisomy & Trisomy \\
\hline 5 & 1 (D) & pT4 & III & 32 & - & - \\
\hline 6 & 4 (D) & pT4 & IV & 22 & - & - \\
\hline 7 & 1 (D) & pT4 & IV & 35 & - & - \\
\hline 8 & 5 (D) & pT4 & II & 20 & Disomy & Disomy \\
\hline 9 & 23 (A) & pT2 & III & 6 & Trisomy & Disomy \\
\hline 10 & 56 (A) & pT2 & II & 5 & - & - \\
\hline 11 & 45 (A) & pT2 & II & 9 & - & - \\
\hline 12 & 42 (D) & pT2 & IV & 20 & - & - \\
\hline 13 & 21 (A) & pT2 & III & 40 & Trisomy & Trisomy \\
\hline 14 & 55 (A) & pT3 & III & 20 & - & - \\
\hline 15 & 20 (D) & pT4 & II & 5 & - & - \\
\hline 16 & $61(\mathrm{~A})$ & pT4 & II & 7 & - & - \\
\hline 17 & 42 (D) & pT4 & II & 1 & - & - \\
\hline 18 & $35(\mathrm{D})^{\star}$ & pT4 & III & 24 & - & - \\
\hline 19 & 24 (D) & pT4 & II & 9 & - & - \\
\hline 20 & 11 (A) & pT4 & III & 6 & Trisomy & Disomy \\
\hline
\end{tabular}

FISH ANALYSIS

Both the chromosome 1 and the chromosome $8 \alpha$ satellite probes produced distinct centromeric hybridisation signals in the metaphase spreads and the surrounding interphase lymphocyte nuclei of the control specimen and the sample material. Based on the evaluation of copy numbers for chromosomes 1 and 8 in the normal liver samples, a chromosome was considered to be trisomic if the percentage of nuclei with three signals exceeded the mean plus three standard deviations. ${ }^{24} 25$ Applying these criteria, all of the nine benign tumours were disomic for either chromosome 1 or 8 , whereas six of seven hepatocellular carcinomas and four of five cholangiocellular carcinomas were trisomic for chromosome 1 and/or chromosome 8 (tables 2 and 3; fig 3).

\section{CLINICAL COURSE}

If patients were divided into those with survival times of less than 12 months or more than 12 months (table 2), hepatocellular carcinoma patients with tumours at the pT3 or pT4 stage had a worse prognosis when MIB-1 indices were $>20 \%$ compared with those with MIB-1 indices $<20 \%$. These reduced survival times had one exception only. This was a patient who underwent liver transplantation (table 2, hepatocellular carcinoma patient 18). He relapsed and died 34 months post-transplantation. Longer survivals (>12 months) were observed in patients with pT3 and pT4 stage tumours with MIB- 1 values $<20 \%$. In the pT 2 patients, tumour stage was the strongest predictor of outcome and was connected with a more favourable prognosis. One exception was hepatocellular carcinoma patient 1 (table 2), who died from sepsis after liver transplantation. Perhaps owing to the relatively low number of cases examined per entity, a direct correlation between chromosome 1 and 8 copy number and tumour proliferation or clinical outcome could not be ascertained (table 2). Also, no correlation was found between survival time and PCNA expression, and the relation described between survival and MIB-1 expression for hepatocellular carcinoma was not demonstrable in cholangiocellular carcinoma (table 3).

\section{Discussion}

Benign proliferation of liver cells in adenomas, focal nodular hyperplasia, or cirrhosis can be distinguished from highly differentiated hepatocellular carcinoma by a significantly higher index of proliferation marked by both the MIB-1 and PC10 antibodies, as shown in this study. This finding should be of practical use because only very small trephine biopsies of liver punctures are used to support the method of surgical intervention. The results presented extend the previous findings of several authors.

Nagao et al noticed an intimate association between the MIB-1 labelling index and the mitotic index in hepatocellular carcinoma, and found the MIB-1 labelling index useful for differentiating between hepatocellular carcinoma and liver cirrhosis. ${ }^{26}$ Grigioni and colleagues ${ }^{27}$ and D'Errico and colleagues ${ }^{28}$ reported a statistically significant influence of Ki67 antigen expression on prognosis when evaluating frozen sections of hepatocellular carcinoma tissue. Similarly, PCNA expression has been suggested to correlate with prognosis or to be suitable in the differential diagnosis of hepatocellular carcinoma. ${ }^{10-1329}$ A recent study by 
Table 3 Results for patients with cholangiocellular carcinoma related to survival

\begin{tabular}{llllll}
\hline Case & $\begin{array}{l}\text { Survival } \\
\text { (months) }\end{array}$ & $\begin{array}{l}\text { Tumour } \\
\text { stage }\end{array}$ & Grade & $\begin{array}{l}\text { MIB-1 } \\
\text { index (\%) }\end{array}$ & $\begin{array}{l}\text { Chromosome 1 } \\
\text { (FISH) }\end{array}$ \\
\hline 21 & $12(\mathrm{D})$ & pT2 & I & 16 & Trisomy \\
22 & $21(\mathrm{D})$ & pT2 & III & 57 & - \\
23 & 46 (D) & pT2 & II & 28 & - \\
24 & 12 (D) & pT2 & II & 19 & - \\
25 & $17(\mathrm{D})$ & pT3 & III & 32 & Trisomy \\
26 & 14 (D) & pT3 & II & 22 & Trisomy \\
27 & 24 (D) & pT3 & I & $<1$ & - \\
28 & 33 (A) & pT3 & II & 4 & - \\
29 & 15 (A) & pT3 & I & 32 & - \\
30 & 9 (D) & pT3 & II & 52 & Disomy \\
31 & 27 (A) & pT4 & II & 12 & - \\
32 & 46 (A) & pT4 & II & 19 & - \\
\hline
\end{tabular}

$\mathrm{D}$, dead; A, alive.

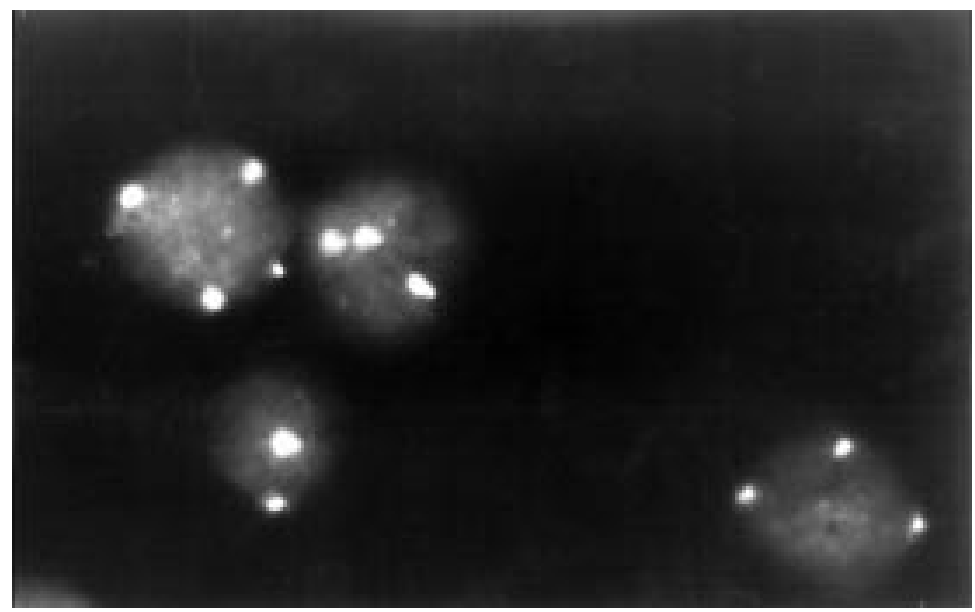

Figure 3 Fluorescence in situ hybridisation with the biotin labelled D8Z1 probe specific for chromosome 8. One cell shows two signals, two cells show three signals, and one cell shows four signals. (Propidium iodine counterstain; original magnification $\times 1000$.)

Soini et al demonstrated that high PCNA expression by itself did not have an impact on survival, but when connected with low apoptosis, it carried a much worse prognosis. ${ }^{30}$

Our results confirm that immunostaining with both the paraffin wax suitable antibody MIB-1 and PC10 is useful for the differential diagnosis of malignant versus benign liver tumours or non-neoplastic liver.

Distinguishing between hepatocellular carcinoma and liver cell adenoma or focal nodular hyperplasia may be especially difficult in small liver biopsies. In this study, Ki67 and PCNA expression were much higher even in low grade hepatocellular carcinoma than in the benign tumours, making evaluation of these antigens very useful in this diagnostic dilemma. However, distinction between the latter tumour entities and non-neoplastic conditions is not possible based solely on the determination of proliferative activity. We did not find Ki67 or PCNA expression to be an independent prognostic parameter in hepatocellular carcinoma or cholangiocellular carcinoma. However, at least in hepatocellular carcinoma, the MIB-1 labelling index appears to be a valuable adjunct to the pTNM stage, because patients with an advanced pTNM stage (pT3/4) and a high MIB-1 labelling index had a much worse prognosis than did patients with pT3/4 and low MIB-1 values. These results are similar to those reported by Suehiro et al, ${ }^{31}$ who found PCNA expression to be a useful marker in addition to the pathological assessment of the tumour (grouping the tumours according to their size).

The positivity rates that have been described for PCNA in different studies are very variable. These differences are probably caused by the problems that are usually encountered with using PCNA as a proliferation marker. ${ }^{32}{ }^{33}$ The PCNA immunoreactivity score depends very much on the sensitivity of the method used including the concentration of antibody, which may even lead to situations where all nuclei in a given sample are stained. ${ }^{8}$ Because the PC 10 antibody appears to overestimate the tumour growth fraction, we think that MIB-1 staining is the more reliable and meaningful technique for evaluating the proliferative activity of liver tumours.

The FISH approach offers another tool for distinguishing between these tumour entities. ${ }^{20}$ It detected aneusomy for chromosomes 1 and/or 8 in 10 of 12 malignant liver tumours, but in none of the liver cell adenomas, focal nodular hyperplasias, or non-neoplastic conditions. Trisomy, as found for both chromosomes in the carcinoma specimens, is incompatible with the explanation of simple endoreduplication, which may occur in non-neoplastic liver. ${ }^{34}$ The advantage of chromosome specific FISH over other methods, such as flow cytometric analysis, is that not only major deviations in DNA content (which occur mainly in advanced cancers) are detected, but also distinct changes that cover only one chromosome.

Hamon-Benais et al reported a smaller series of primary liver tumours that they investigated by interphase FISH. Interestingly, they also found a benign tumour (nodular hyperplasia) with a monosomy for chromosome $17 .^{35}$

In contrast to our study, when evaluating 25 hepatocellular carcinomas, Kimura et al were able to demonstrate a positive relation between polysomy for chromosome 17 and proliferative activity as well as histological grade of malignancy. ${ }^{36}$ They concluded that in situ hybridisation analysis might be a valuable tool for predicting malignant potential in hepatocellular carcinoma, although no clinical data were presented.

In conclusion, determination of the proliferating cell fraction as well as FISH analysis for numerical chromosome aberrations is valuable in the differential diagnosis of liver tumours, as it is particularly useful in distinguishing hepatocellular carcinoma from liver cell adenoma or focal nodular hyperplasia. Moreover, prognostic subgroups within hepatocellular carcinoma can be defined by evaluating the proliferation index, thus offering a valuable adjunct to pTNM staging. Because PCNA expression seems to overestimate the actual growth fraction, is more prone to artefacts, and has no clear connection with clinical behaviour, it is concluded that the measurement of Ki67 expression is preferable for the analysis of proliferative capacity.

1 Brown DC, Gatter KC. Monoclonal antibody Ki67: its use in histopathology. Histopathology 1990;17:489-503.

2 Cattoretti G, Becker M, Key G, et al. Monoclonal antibodies against recombinant parts of the Ki-67 antigen (MIB 1 and MIB 3) detect proliferating cells in microwaveand MIB 3) detect proliferating cells in microwave-
processed formalin-fixed paraffin sections. $\mathcal{F}$ Pathol 1992; 168:357-63. 
3 Bravo R, Frank R, Blundell PA, et al. Cyclin/PCNA is the auxiliary protein of DNA polymerase delta. Nature auxiliary protein

4 Prelich G, Tan CK, Kotsura M, et al. Functional identity of proliferating cell nuclear antigen and a DNA polymerasedelta auxiliary protein. Nature $1987 ; 326: 517-20$.

5 Yu CW, Woods AL, Levison DA. The assessment of cellular proliferation by immunohistochemistry: a review of currently available methods and their applications. Histochem $\mathcal{F}$ 1992;24:121-31

6 McCormick D, Yu C, Hobbs C, et al. The relevance of antibody concentration to the immunohistological quantitation
of cell proliferation associated antigens. Histopathology 1993;22:543-7.

7 Bravo R, Macdonald-Bravo M. Existence of two populations of cyclin/proliferating cell nuclear antigen during the cell cycle. Association with DNA replication sites. I Cell Biol 1987; 105:1549-54.

8 Jain S, Filipe MI, Hall PA, et al. Proliferating cell nuclear antigen (PCNA) prognostic value in gastric carcinoma. $\mathcal{F}$ antigen (PCNA) prognostic
Clin Pathol 1991;44:655-9.

9 Kawakita N, Seki S, Sakaguchi H, et al. Analysis of proliferating hepatocytes using a monoclonal antibody against proliferating cell nuclear antigen/cyclin i from various liver diseases fixed in formaldehyde. $A m \mathcal{F}$ Pathol 1992;140:513-20.

10 Terada T, Nakanuma Y. Cell proliferative activity in adenomatous hyperplasia of the liver and small hepatocellular carcinoma. Cancer 1992;70:591-8.

11 Adachi E, Hashimoto H, Tsuneyoshi M. Proliferating cell nuclear antigen in hepatocellular carcinoma and small cell liver dysplasia. Cancer 1993;72:2902-9.

12 Kitamoto M, Nakanishi R, Kira S, et al. The assessment of proliferating cell nuclear antigen immunohistochemical staining in small hepatocellular carcinoma and its relationship to histologic characteristics and prognosis. Cancer 1993;72:1859-65.

13 Ojanguren I, Ariza A, Llatjos M, et al. Proliferating cell nuclear antigen expression in normal, regenerative, and nuclear antigen expression in normal, regenerative, and neoplastic liver: a fine needle aspiration
biopsy study. Hum Pathol 1993;24:905-8.

14 Pichlmayr R, Weimann A, Steinhoff G, et al. Liver transplantation for hepatocellular carcinoma: clinical results and future aspects. Cancer Chemother Pharmacol 1992; 31(suppl 1): 157-61.

15 Sandberg AA, Turc-Carel C. The cytogenetics of solid tumours. Cancer 1987;59:387-95.

16 Simon D, Munou SJ, Maddrey WC, et al. Chromosomal rearrangements in a primary hepatocellular carcinoma. Cancer Genet Cytogenet 1990;45:255-60.

17 Bardi G, Johansson B, Pandis N, et al. Cytogenetic findings in three primary hepatocellular carcinomas. Cancer Genet Cytogenet 1992;58:191-5.

18 Fujiwara Y, Monden M, Mori T, et al. Frequent multiplication of the long arm of chromosome 8 in hepatocellular carcinoma. Cancer Res 1993;53:857-60.

19 Werner M, Nolte $M$, Klempnauer J, et al. Chromosome 1 abnormalities in hepatocellular carcinoma. Cancer Genet Cytogenet 1993;66:30.

20 Nasarek A, Werner $M$, Nolte $M$, et al. Trisomy 1 and 8 occur frequently in hepatocellular carcinoma but not in liver cell adenoma and focal nodular hyperplasia. A fluorescence in situ hybridization study. Virchows Arch 1995;427:373-8.
21 Hopman AHN, Poddighe PJ, Smeets WGB, et al. Detection of numerical chromosome aberrations in bladder cancer by in situ hybridization. Am F Pathol 1989;135:1105-16.

22 Edmondson HA, Steiner PE. Primary carcinoma of the iver: a study of 100 cases among 48,900 necropsies. Cancer $1954 ; 7: 462-503$

23 Cordell JL, Falini B, Erber WN, et al. Immunoenzymatic labeling of monoclonal antibodies using immune complexes of alkaline phosphatase and monoclonal antialkaline phosphatase (APAAP complexes). $\mathcal{F}$ Histochem Cytochem 1984;32:219-29.

24 Ward BE, Gersen SL, Carelli MP, et al. Rapid prenatal diagnosis of chromosomal aneuploidies by fluorescence in situ hybridization: clinical experience with 4,500 specimens. Am 7 Hum Genet 1993;52:854-65.

25 Takahashi S, Qian J, Brown JA, et al. Potential marker of prostate cancer aggressiveness detected by fluorescence in situ hybridization in needle biopsies. Cancer Res 1994;54: 3574-9.

26 Nagao $T$, Kondo F, Sato $T$, et al. Immunohistochemical detection of aberrant p53 expression in hepatocellular carcinoma: correlation with cell proliferative activity indices, including mitotic index and MIB-1 immunostaining. Hum Pathol 1995;26:326-3.

27 Grigioni WF, Garbisa S, D'Errico A, et al. Evaluation of hepatocellular carcinoma aggressiveness by a panel of extracellular matrix antigens. Am f Pathol 1991;138:64754.

28 D'Errico A, Grigioni WF, Fiorentino M, et al. Overexpression of p53 protein and Ki67 proliferative index in hepatocellular carcinoma: an immunohistochemical study on 109 Italien patients. Pathol Int 1994;44:682-7.

29 Ng IOL, Path MRC, Lai ECS, et al. Prognostic significance of proliferating cell nuclear antigen expression in hepatocellular carcinoma. Cancer 1993;73:2268-74.

30 Soini Y, Virkajärvi N, Lehto VP, et al. Hepatocellular carcinomas with a high proliferation index and a low degree of apoptosis and necrosis are associated with a shortened survival. Br f Cancer 1996;73:1025-30.

31 Suehiro T, Matsumata T, Itasaka $\mathrm{H}$, et al. Clinicopathologic features and prognosis of resected hepatocellular carcinomas of varied sizes with special reference to proliferating cell nuclear antigen. Cancer 1995;76:399-405.

32 Leong ASY, Milios J, Tang SK. Is immunolocalisation of proliferating cell nuclear antigen (PCNA) in paraffin sections a valid index of cell proliferation? Appl Immunohistochem 1993;1:127-35.

33 McCormick D, Hall PA. The complexities of proliferating cell nuclear antigen. Histopathology 1992;21:591-4.

34 Biesterfeld S, Gerres K, Fischer-Wein G, et al. Polyploidy in non-neoplastic tissues. F Clin Pathol 1994;47:38-42.

35 Hamon-Benais $\mathrm{C}$, Ingster $\mathrm{O}$, Terris $\mathrm{B}$, et al. Interphase cytogenetic studies of human hepatocellular carcinomas by fluorescent in situ hybridization. Hepatology 1996;23:42935 .

36 Kimura H, Kagawa K, Deguchi T, et al. Cytogenetic analyses of hepatocellular carcinoma by in situ hybridization with a chromosome-specific DNA probe. Cancer 1996;77: $271-7$ 